\title{
Polypyrrole-coated Graphite Fluorides with High Energy and High Power Densities for Li/CF $x$ battery
}

\author{
Ling Zhu, Lei Li, Jie Zhou, Yong Pan", Weixin Lei ${ }^{*}$, Zengsheng Ma \\ Hunan Provincial Key Laboratory of Thin Film Materials and Devices and School of Materials \\ Science and Engineering, Xiangtan University, Hunan 411105 China \\ *E-mail: ypan@xtu.edu.cn, wxlei@xtu.edu.cn
}

doi: $10.20964 / 2016.08 .06$

Received: 29 April 2016 / Accepted: 23 May 2016 / Published: 7 July 2016

\begin{abstract}
Polypyrrole (PPy) coated graphite fluorides $\left(\mathrm{CF}_{x}\right)$ composites have been prepared via in situ chemical oxidative polymerization. The influence of coating thickness on the electrochemical performances of PPy-coated $\mathrm{CF}_{x}\left(\mathrm{CF}_{x} @ \mathrm{PPy}\right)$ cathodes has been investigated. The results show that the rate capability of $\mathrm{CF}_{x} @ \mathrm{PPy}$ cathodes are improved compared with that of pristine $\mathrm{CF}_{x}$ cathode. The PPy coating serves as the path for charges transfer from the surface of $\mathrm{CF}_{x}$ to the reaction interface. The conductivity of $\mathrm{CF}_{x} @$ PPy increases with the growing PPy coating, however, too thick PPy coating may inhibit the lithium ions transfer and even pull down the discharge capacity. Finally, the $\mathrm{CF}_{x} @ \mathrm{PPy}$ composite with a PPy coating thickness of $80 \mathrm{~nm}$ exhibits a superior rate capability and a maximum delivered power density up to $7091 \mathrm{~W} \mathrm{~kg}^{-1}$ at $6 \mathrm{C}$.
\end{abstract}

Keywords: Graphite fluoride; Polypyrrole; $\mathrm{CF}_{x} @ \mathrm{PPy}$; battery

\section{FULLTEXT}

(C) 2016 The Authors. Published by ESG (www.electrochemsci.org). This article is an open access article distributed under the terms and conditions of the Creative Commons Attribution license (http://creativecommons.org/licenses/by/4.0/). 